\title{
Ultraviolet radiation-induced tumor necrosis factor alpha, which is linked to the development of cutaneous SCC, modulates differential epidermal microRNAs expression
}

\author{
Ashok Singh ${ }^{1}$, Estelle Willems ${ }^{1}$, Anupama Singh ${ }^{1}$, Bilal Bin Hafeez ${ }^{1}$, Irene M. Ong ${ }^{2}$, \\ Suresh L. Mehta ${ }^{3}$ and Ajit Kumar Verma ${ }^{1}$ \\ ${ }^{1}$ Department of Human Oncology, Wisconsin Institutes for Medical Research, Paul P. Carbone Comprehensive Cancer Center, \\ School of Medicine and Public Health, University of Wisconsin, Madison, WI, USA \\ 2 Biostatistics and Medical Informatics, Medical Science Center, University of Wisconsin, Madison, WI, USA \\ ${ }^{3}$ Department of Neurological Surgery, University of Wisconsin, Madison, WI, USA \\ Correspondence to: Ajit Kumar Verma, email: akverma@facstaff.wisc.edu \\ Keywords: microRNA, TNFa, SCC, UVR \\ Received: November 04, 2015 Accepted: January 29, $2016 \quad$ Published: February 22, 2016
}

\section{ABSTRACT}

Chronic exposure to ultraviolet radiation (UVR) is linked to the development of cutaneous squamous cell carcinoma (SCC), a non-melanoma form of skin cancer that can metastasize. Tumor necrosis factor-alpha (TNFa), a pro-inflammatory cytokine, is linked to UVR-induced development of SCC. To find clues about the mechanisms by which TNFa may promote UVR-induced development of SCC, we investigated changes in the expression profiling of microRNAs (miRNA), a novel class of short noncoding RNAs, which affects translation and stability of mRNAs. In this experiment, TNFa knockout (TNFa KO) mice and their wild type (WT) littermates were exposed to acute UVR $\left(2.0 \mathrm{~kJ} / \mathrm{m}^{2}\right)$ and the expression profiling of epidermal miRNA was determined $4 \mathrm{hr}$ post UVR exposure. TNFa deletion in untreated WT mice resulted in differential expression (log fold change>1) of seventeen miRNA. UVR exposure in WT mice induced differential expression of 22 miRNA. However, UVR exposure in TNFa KO mice altered only two miRNAs. Four miRNA, were differentially expressed between WT+UVR and TNFa KO+UVR groups. Differentially expressed selected miRNAs were further validated using real time PCR. Few of the differentially expressed miRNAs (miR-31-5p, miR-196a-5p, miR-127-3p, miR-206-3p, miR-411-5p, miR-709, and miR322-5p) were also observed in UVR-induced SCC. Finally, bio-informatics analysis using DIANA, MIRANDA, Target Scan, and miRDB algorithms revealed a link with major UVR-induced pathways (MAPK, PI3K-Akt, transcriptional mis-regulation, Wnt, and TGF-beta).

\section{INTRODUCTION}

Ultraviolet radiation (UVR) is a potent environmental carcinogenic agent, and its chronic exposure leads to cutaneous Squamous Cell Carcinoma (cSCC) [1]. Cutaneous SCC is the second most common non melanoma skin cancer (NMSC) with approximately 250,000 new cases per year [2]. Cutaneous SCC originates from the epidermal keratinocytes [2]. UVR exposure can directly damage the cellular DNA [3, 4]. UVR induces DNA lesions, which remains unrepaired and accumulated on replication resulting in the expansion of initiated clones. The whole process is facilitated by aberrant gene expression during initiation process of carcinogenesis. Recently, it has been observed that $>60 \%$ of human protein coding genes are regulated by microRNAs (miRNAs), a novel class of regulators [5].

MiRNAs are small non-protein coding RNAs and endogenous in their origin. The nucleotide size of these miRNAs ranges from 19-22. These small endogenous regulators play important roles in post-transcriptional process of various protein coding genes $[6,7]$. Such miRNA regulation is mediated by the binding of miRNA with a partially complimentary target site within the 3 ' untranslated region (3'-UTR) of their target mRNA [5]. Interestingly, a single miRNA is able to suppress several 
target mRNAs; and in turn be targeted by multiple miRNAs [8]. Various components of miRNA pathways are found to be affected in epithelial skin cancer [9-12]. Also, the UVA and UVB irradiation differentially regulate miRNA expression in human primary keratinocytes [13]. Identification of novel miRNAs involved in UVR-induced skin cancer [14] may be useful as early diagnostic markers, and to precisely define cancer stages and its progression. However, the literature for UVR-induced miRNAs in cutaneous skin cancer is limited [15].

UVR exposure in mice skin results in elevated release of various pro-inflammatory cytokines including tumor Necrosis Factor alpha $(\mathrm{TNF} \alpha)[16,17]$. It has been observed that cutaneous damage due to UVR is less in $\mathrm{TNF} \alpha$ knock out (TNF $\alpha \mathrm{KO}$ ) mice compared to their wild type $[17,18]$. Additionally, $\mathrm{TNF} \alpha \mathrm{KO}$ and $\mathrm{TNF} \alpha$ receptor $\mathrm{KO}$ mice are resistant to development of skin cancer elicited by repeated UVR exposure $[19,20]$. However, a precise molecular mechanism by which TNF $\alpha$ signals UVR-induced skin carcinogenesis is not understood clearly.

In this communication, we determined whether TNF $\alpha$ deletion in mice affects UVR-induced expression profile of epidermal miRNAs. We report for the first time: a) UVR-induced expression profile of epidermal miRNAs in wild type (WT) and TNF $\alpha \mathrm{KO}$ mice, b) validation of the differentially expressed epidermal miRNAs using real time PCR, c) expression pattern of miRNAs in UVRinduced SCC samples, and d) bio-informatics analysis of UVR-induced epidermal miRNAs and their targeted genes.

\section{RESULTS}

\section{Differential expression of miRNAs responsive to acute UVR exposure in the epidermal skin of WT and TNF $\alpha$ KO mice}

To find clue about the UVR-induced miRNA modulation, the mice were divided into two groups. The first group was untreated (WT, TNF $\alpha \mathrm{KO}$ ), and the second group (WT+UVR, TNF $\alpha \mathrm{KO}+\mathrm{UVR}$ ) was exposed to acute UVR (single dose, $2.0 \mathrm{~kJ} / \mathrm{m}^{2}$ ). Total RNA from the whole skin was isolated for global miRNA profiling 4 hr post UVR. We found differential expression (log fold change $>1$ ) of 22 miRNAs between the WT and WT+UVR group and 17 miRNAs between the WT and TNF $\alpha \mathrm{KO}$ group (Tables 1, 2). Two miRNAs were differentially expressed between $\mathrm{TNF} \alpha \mathrm{KO}$ and $\mathrm{TNF} \alpha \mathrm{KO}+\mathrm{UVR}$, and four miRNAs between $\mathrm{WT}+\mathrm{UVR}$ and TNF $\alpha \mathrm{KO}+\mathrm{UVR}$ groups (Table 3,4). A comparison between WT and WT+UVR group revealed the up regulation of six miRNAs (miR-31-5p, miR-31-3p, miR-709, miR-5617, miR-691, and miR-185-3p) and down regulation of sixteen
miRNAs (see Table 1). There were two highly suppressed miRNAs (log fold change $=2$ ) miR-196a-5p and miR196b-5p following acute UVR exposure compared to untreated WT mice. Also, miRNAs miR-31-5p (log FC $=2)$ and miR-31-3p ( $\log \mathrm{FC}=1.7)$ were up-regulated due to acute UVR treatment in WT mice compared to untreated littermates. Moreover, a comparison between WT and TNF $\alpha \mathrm{KO}$ mice, revealed the up regulation of one microRNA (miR-3065-3p) and down regulation of sixteen miRNAs (Table 2). Two miRNAs miR-196b-5p and miR-206-3p were up regulated between $\mathrm{TNF} \alpha \mathrm{KO}$ and $\mathrm{TNF} \alpha \mathrm{KO}+\mathrm{UVR}$.

Interestingly, miR-3065-3p, miR-541-5p, and miR-322-5p are exclusively and differentially expressed between WT and TNF $\alpha \mathrm{KO}$ mice skin following acute UVR exposure (Table 2). Also, miR-185-3p is not differentially expressed between WT and TNF $\alpha \mathrm{KO}$ mice. A comparison between WT vs WT+UVR, and TNF $\alpha$ vs TNF $\alpha$ KO mice revealed that there are common miRNAs, which are differentially expressed among these groups. Literature mining revealed that the differentially expressed microRNAs miR-196a-5p, miR-127-3p and miR-206-3p are found to be expressed in hair follicles of mice skin [21]. Also, we observed increased epidermal hyperplasia in $24 \mathrm{hr}$ post UVR treated WT mice compared to $\mathrm{TNF} \alpha \mathrm{KO}$ (Figure 1A). There was no hyperplasia in $\mathrm{TNF} \alpha \mathrm{KO}$ mice. Hierarchical clustering analysis based on the 48 differentially regulated miRNAs completely distinguished WT and TNF $\alpha \mathrm{KO}$ mice from their UVR treated littermates (Figure 1B).

To confirm the miRNA Array expression data, we further determined the expression pattern of selected miRNAs using SYBR green based chemistry. The expression patterns of miR-31-5p, miR-127-3p, miR-4115p, miR-322-5p, miR-709, and miR-379-5p were similar to the microarray results in our profiling study among four mice groups namely WT, WT + UVR, TNF $\alpha \mathrm{KO}$, and $\mathrm{TNF} \alpha \mathrm{KO}+\mathrm{UVR}$ following acute UVR treatment (Figure 2A). Only miR-3065-3p was up-regulated in TNF $\alpha \mathrm{KO}$ mice compared to their WT littermates. Validation data with RT-PCR confirms the findings of global miRNA array platform.

\section{Differential regulation of miRNAs in SCC samples induced by UVR}

In our miRNA global expression profiling study most of the miRNAs were down regulated except few of the up-regulated miRNAs (Table 1-3). To determine the expression pattern of validated miRNAs in SCC samples harvested from FVB mice following UVR-induced carcinogenesis. Expression pattern of UVR-induced SCC was compared with the uninvolved skin harvested from the same group of mice. The miRNA miR-31-5p was up regulated in three SCC samples compared to uninvolved skin. We also determined the expression pattern of 
(A).

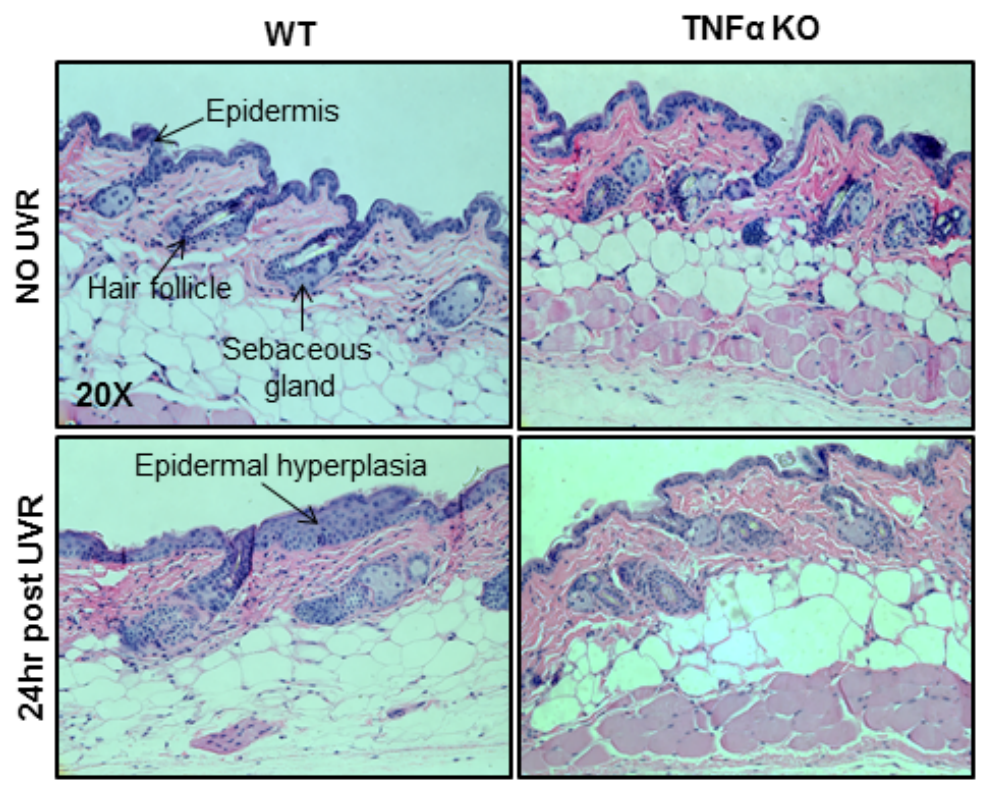

(B).
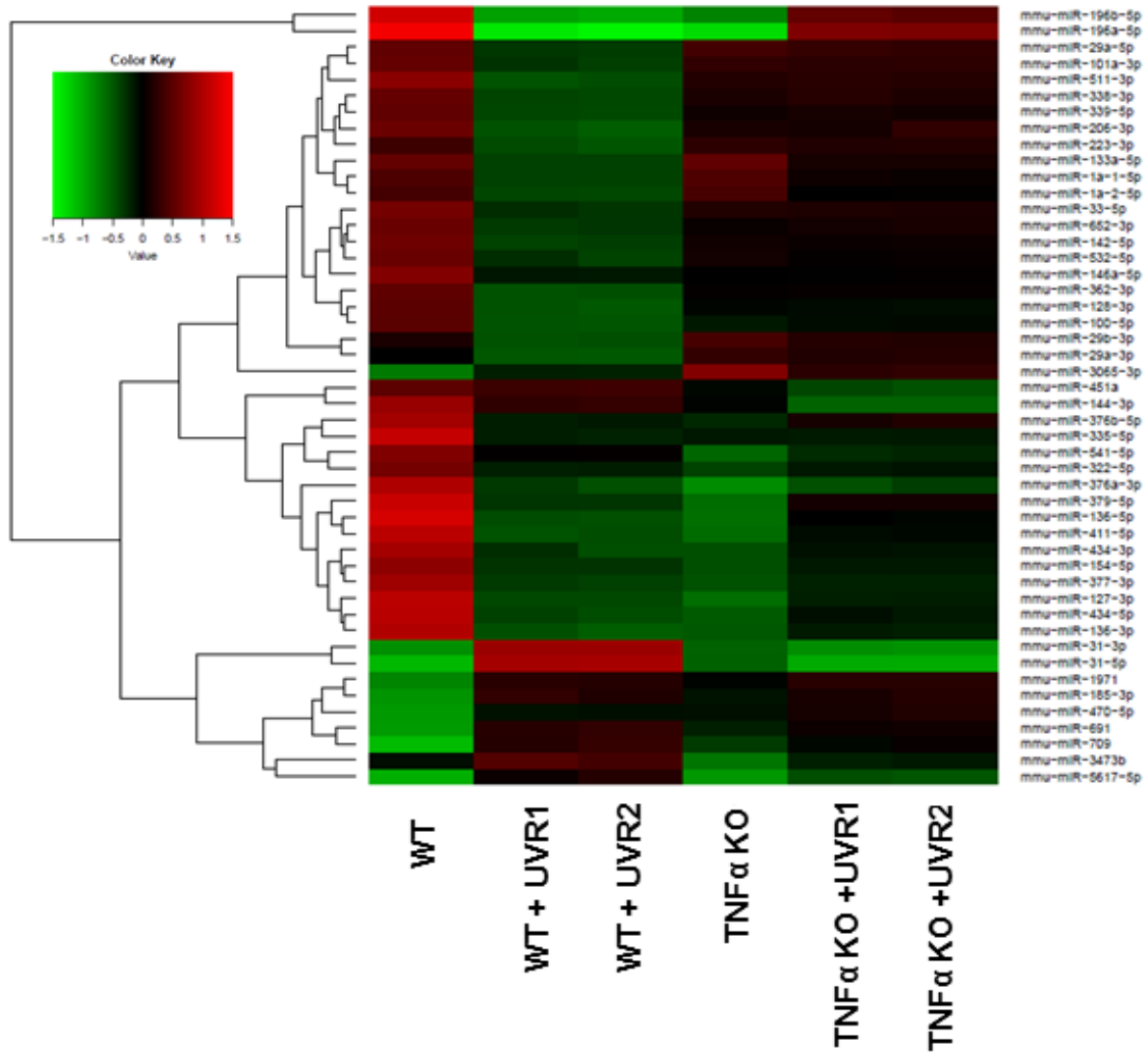

Figure 1: Skin histology and hierarchical clustering of miRNA expression. A. is showing the representative pictures of skin histology and UVR-induced hyperplastic epidermis in the skin of WT, and TNF $\alpha$ KO mice. Briefly, mice were exposed once to UVR (2.0 $\left.\mathrm{kJ} / \mathrm{m}^{2}\right)$, and were sacrificed at $24 \mathrm{~h}$ post UVR. For histochemistry, mice skin specimen ( $n=3$ each) were processed for H \& E staining. All H \& E pictures were taken in a Nuance bright field microscope at 20X magnification. The $\mathbf{B}$. is showing the clustering performed on the top forty eight miRNAs with highest standard deviation. The values of normalized log ratio were used for the analysis. The heat map diagram is showing the result of a two-way hierarchical clustering of miRNAs in mice samples ( $n=2$ each). The complete-linkage method and the Euclidean distance measure are used for the miRNA clustering. Each row in the clustering diagram represents miRNA and each column represents a mice sample. The left side of the $\mathbf{B}$. is showing clustering tree. The color key in top left of the $\mathbf{B}$. is showing the relative expression level of miRNAs. Red and green colors in the clustering diagram are showing higher and lower expression of miRNAs than the reference channel respectively. 
miRNAs such as miR-196a-5p, miR-127-3p, miR-411-5p, and miR-206-3p in UVR-induced SCC samples from wild type FVB mice. Some of the miRNAs were significantly down-regulated [miR-196a-5p $\quad(p=0.05)$, miR-709-5p $(p=0.003), \operatorname{miR}-206-3 p(0.001), \operatorname{miR}-411-5 p \quad(p=0.03)]$ along with others miR-127-3p, miR-322-5p in UVRinduced SCC samples $(n=3)$ compared to the uninvolved skin $(n=3)$ (Figure 2B).

\section{Bioinformatics analysis reveals dysregulation of UVR-induced target genes and their targeted pathways following miRNA alteration}

To determine the functional relevance of the up- and down-regulated miRNAs following UVR, we predicted targets of these miRNAs in skin. We used four microRNA target prediction web tools namely DIANA, MIRANDA, Target Scan, and miRDB to predict the target genes modulated by UVR and TNF $\alpha$ (Supplementary Tables S1 and S2). Our software based prediction indicates multiple gene targets for miRNAs (Table 1-4). We found that a minimum of 12 to a maximum of 613 genes were targeted by miRNAs namely miR-127-3p and miR-322-5p respectively (Tables 1-4).

As it is known that miRNAs are key regulators in various biological processes and their functional outcomes, we investigated the combinatorial effect of all up- and down-regulated miRNAs in various biological pathways following acute UVR exposure. In such enrichment analysis of miRNAs, we grouped them separately to determine their functional influence in various biologically relevant pathways using DIANA miRPath v.2.0 (Figure $3 \mathrm{~A}-\mathrm{B})$. We found that the nine pathways related to transcriptional misregulation in cancer, biotin metabolism, MAPK signaling, lysine degradation, ubiquitin mediated proteolysis, cell cycle, gap junction, TGF- $\beta$ signaling, and circadian rhythm, are affected due to sixteen downregulated miRNAs between WT and WT+UVR mice; and seventeen down-regulated microRNAs between WT and $\mathrm{TNF} \alpha \mathrm{KO}$ mice. Importantly, the "transcriptional misregulation in cancer" pathway is affected by most of our differentially expressed miRNAs (miR-136-5p, miR196a-5p, miR-196b-5p, miR-376a-3p, miR-335-5p, and miR-206-3p) significantly ( $<<0.001)$ (Figure $3 A$ ).

The combinatorial effect of six up-regulated miRNAs (miR-691, miR-709, miR-31-5p, miR-5617$5 p$, miR-31-3p, and miR-185-3p) leads to the following important signaling pathways such as MAPK signaling, pathways in cancer, $\mathrm{Ca}^{+2}$ signaling, ubiquitin proteolysis, lysine degradation, endocytosis, glycosaminoglycan biosynthesis (chondroitin sulfate and keratin sulfate), Fc gamma-mediated phagocytosis, amphetamine addiction, bladder cancer, ECM-receptor interaction, steroid

(A)

(i)

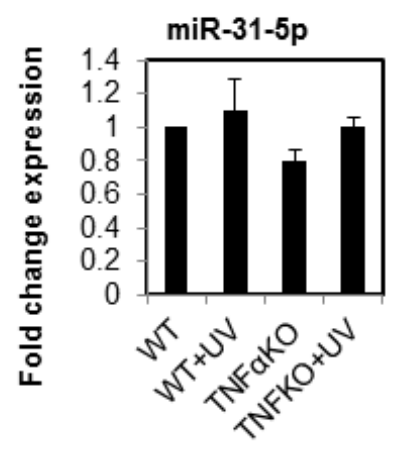

(iv)

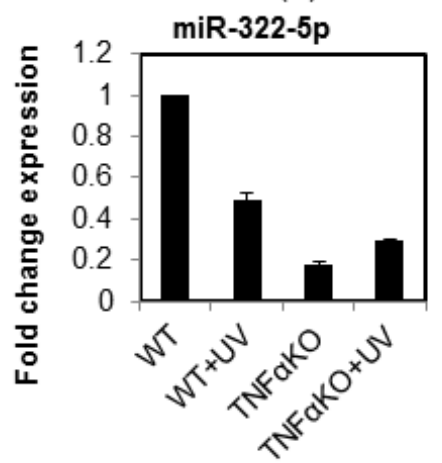

(ii)

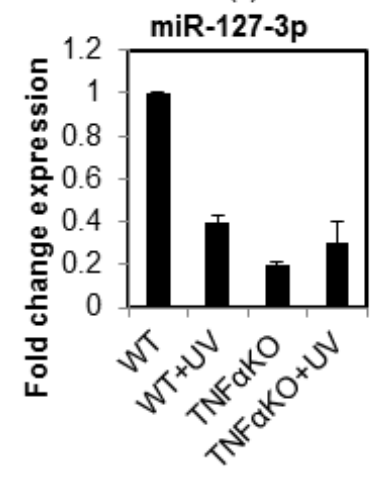

(v)

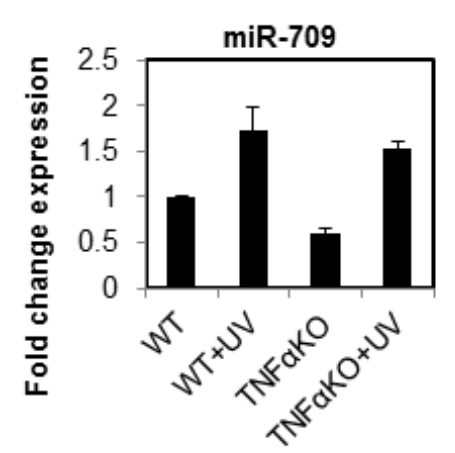

(iii)

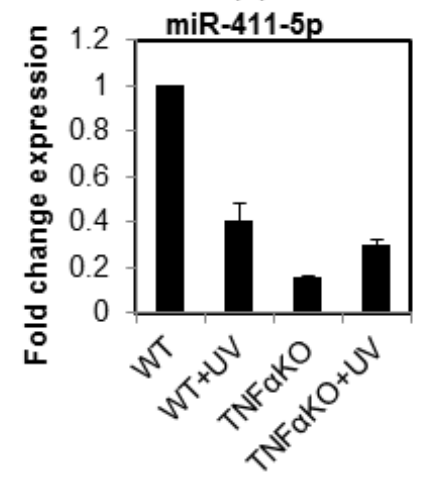

(vi)

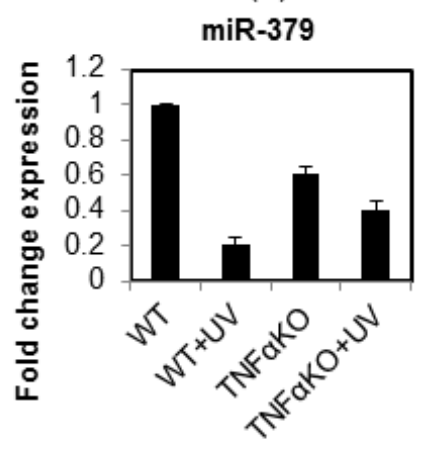


(B)

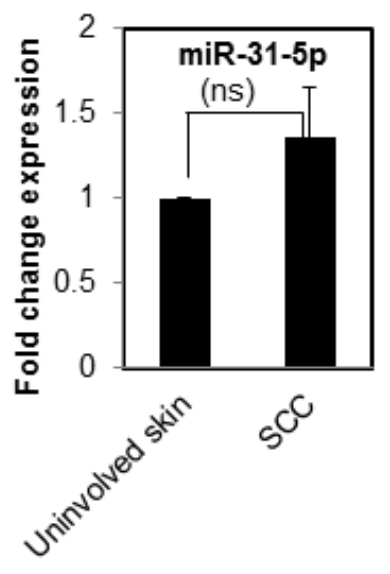

(iv)

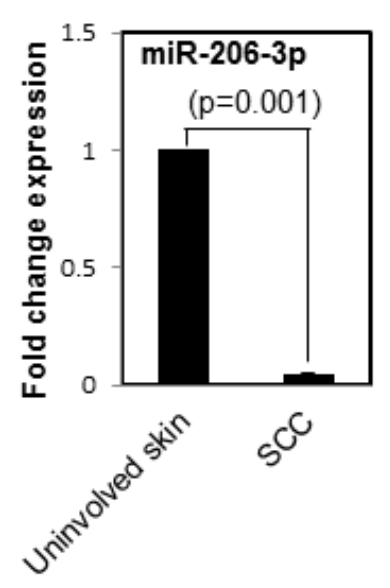

(ii)

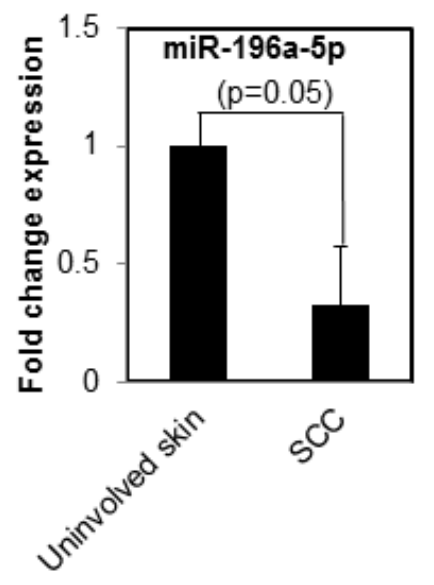

(v)

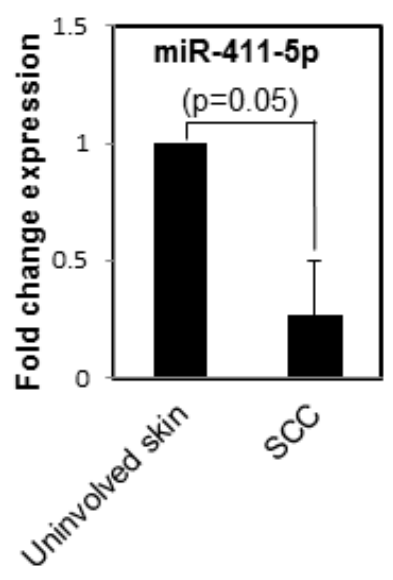

(Vii)

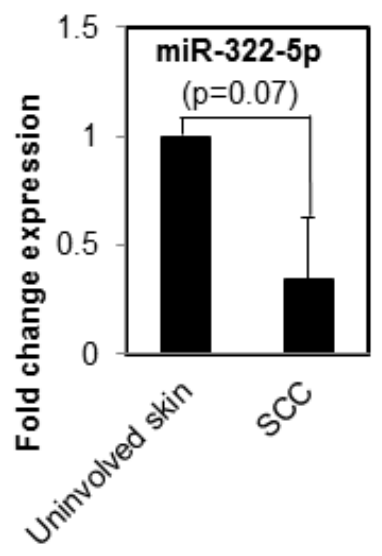

(iii)

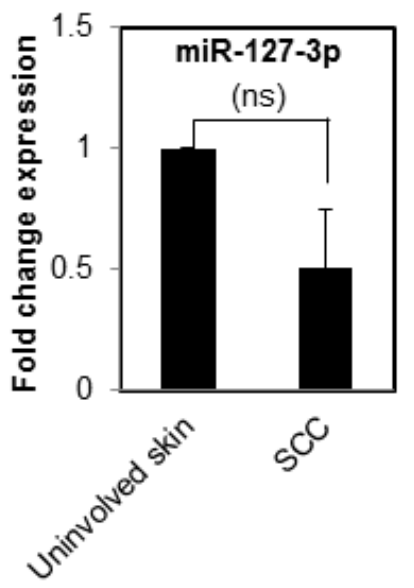

(vi)

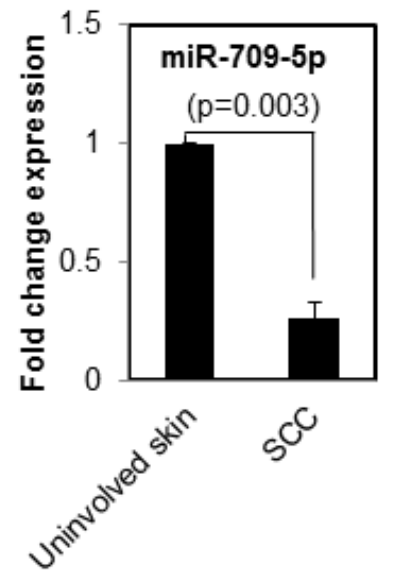

Figure 2: Validation of differentially expressed miRNAs using real time PCR in WT, TNF $\alpha$ KO and their respective UVR treated mice group. A. is showing the real time expression pattern of miR-31-5p, miR-127-3p, miR-411-5p, miR-322-5p, miR709, and miR-379 in WT, WT + UVR, TNF $\alpha$ KO and TNF $\alpha$ KO + UVR mice. The data presented in the each bar diagram is the mean \pm SE from triplicate sample in all four mice groups. The detail of the method is discussed in materials and methods section. The $\mathbf{B}$. is showing the expression pattern of miRNAs miR-31-5p, miR-196-5p, miR-127-3p, miR-206-3p, miR-411-5p, miR-709-5p, and miR-322-5p in UVRinduced SCC samples from wild type FVB mice. Each value is the mean \pm SE from three UVR-induced SCC samples ( $\mathrm{n}=3$ ). (Abbreviation: ns $=$ non-significant $)$. 
biosynthesis, dopaminergic synapse, and steroid hormone biosynthesis using pathways union mode. These pathways are significantly ( $\mathrm{p}=0.05$ and 0.001 ) targeted due to acute UVR exposure between UVR-treated FVB mice and their untreated littermates. In this analysis, a maximum of nine and seven pathways are affected due to miR-185-3p, and miR-31-5p respectively. Taken together both down- and up-regulated miRNA affects some common pathways which are implicated in UVR-induced carcinogenesis.

\section{DISCUSSION}

UVR, the component of sunlight has been linked to the development of non-melanoma skin cancer [1]. TNF $\alpha$ is up-regulated in response to UVR exposure. TNF $\alpha$ has been reported an endogenous mouse skin tumor promoter. The TNF $\alpha$ deficient mice are resistant to the skin cancer development induced by UVR and DMBA-TPA tumor promotion protocol [19]. But the molecular mechanism linked to the resistance to UVR is not clear. Present miRNA profiling study compares the miRNA profile among WT, TNF $\alpha \mathrm{KO}$, and their UVR-treated littermates, and further predicts the probable miRNA targets of differentially expressed miRNAs in mouse skin. We observed the differential expression of 22 miRNAs due to UVR in WT mice and 17 miRNAs between WT and TNF $\alpha$ KO group. Fourteen common miRNAs are differentially expressed among these four groups (Table 1-3). A total of sixteen microRNAs are down regulated in $\mathrm{TNF} \alpha \mathrm{KO}$

(A)

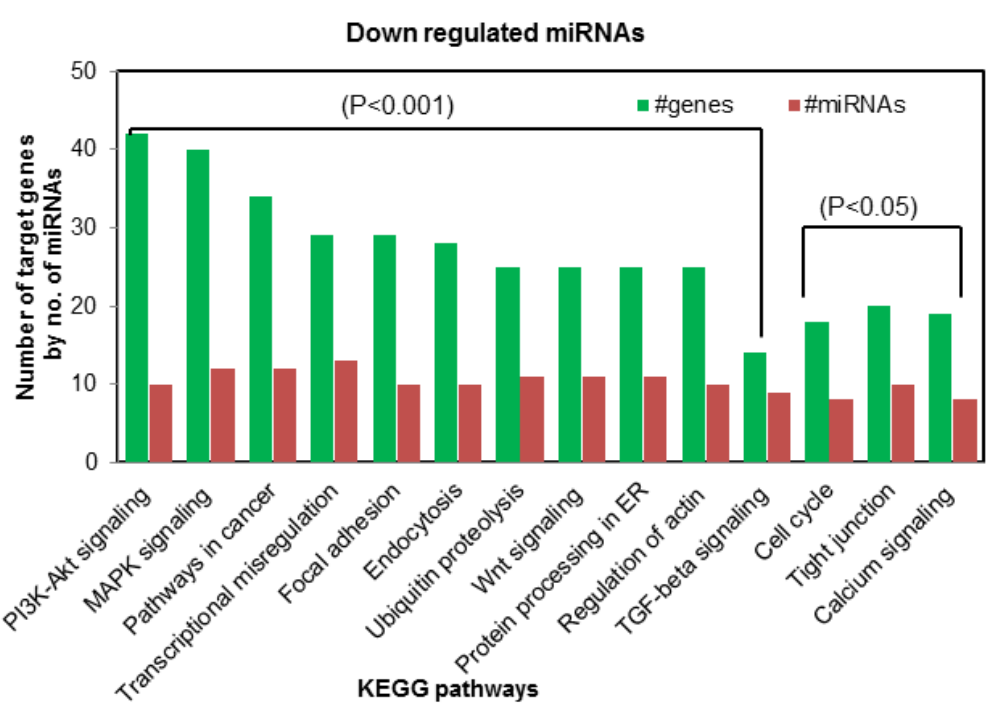

(B)

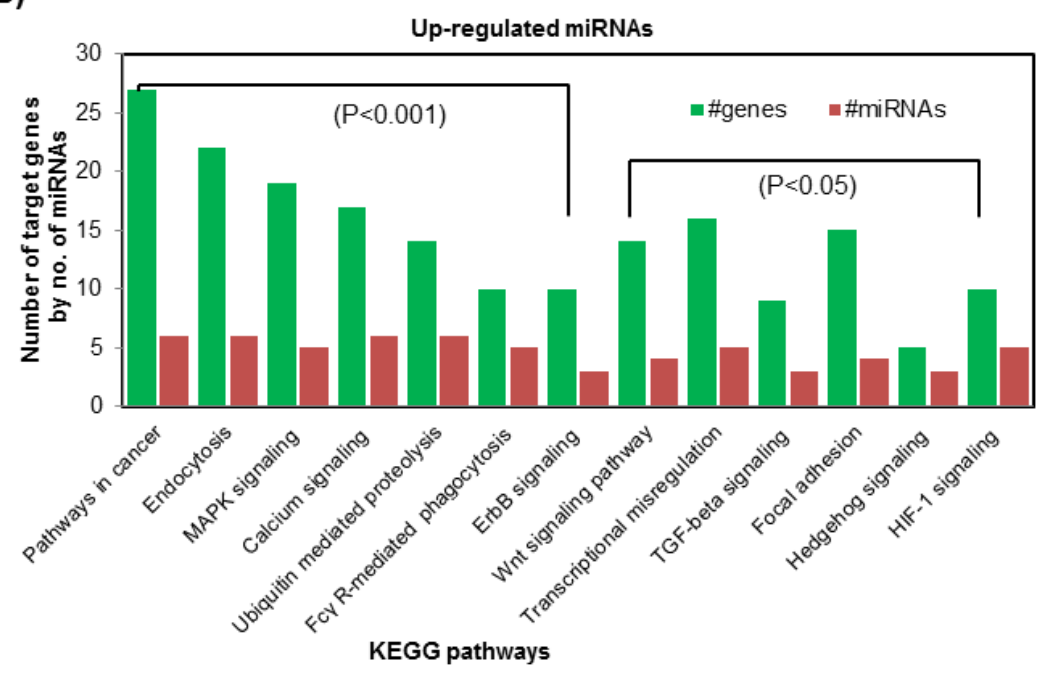

Figure 3: Bioinformatics analysis of differentially expressed miRNAs following acute UVR exposure in WT and TNFa KO mice. A. and B. are the top KEGG pathways of biological function of the targets of down- and up-regulated mouse miRNAs that were observed to be altered at $4 \mathrm{hr}$ post UVR treatment in WT and TNF $\alpha \mathrm{KO}$ mice. The analysis in $\mathbf{A}$. and $\mathbf{B}$. is based on the combinatorial effects of down- and up-regulated miRNAs. A detail about the bio-informatics analysis is given in materials and methods section. 
Table 1: Differential expression pattern of UVR-induced miRNAs in WT and their UVR treated littermates

\begin{tabular}{|c|c|c|c|c|c|c|}
\hline microRNAs & Location on chromosome & WT & WT+UVR & $\begin{array}{l}\text { Log Fold } \\
\text { Change }\end{array}$ & $\begin{array}{l}\text { Adjusted } \\
p \text {-value }\end{array}$ & $\begin{array}{l}\text { Total \# of gene } \\
\text { targets }\end{array}$ \\
\hline miR-127-3p & chr12: $109592846-109592915[+]$ & 1.089 & -0.401 & -1.49 & $1.11 \mathrm{E}-06$ & 12 \\
\hline $\operatorname{miR}-136-3 p$ & chr12: $109595327-109595388[+]$ & 1.027 & -0.48 & -1.507 & 2.04E-06 & 32 \\
\hline miR-136-5p & chr12: $109595327-109595388[+]$ & 1.246 & -0.431 & -1.677 & $1.11 \mathrm{E}-06$ & 275 \\
\hline $\operatorname{miR}-154-5 p$ & chr12: $109738433-109738498[+]$ & 0.811 & -0.283 & -1.094 & 2.04E-06 & 201 \\
\hline miR-185-3p & chr16: $18327401-18327465$ [-] & -0.853 & 0.225 & 1.078 & $3.10 \mathrm{E}-05$ & 203 \\
\hline $\operatorname{miR}-196 a-5 p$ & chr11: $96265164-96265265[+]$ & 1.441 & -1.405 & -2.846 & $1.11 \mathrm{E}-06$ & 137 \\
\hline miR-196b-5p & chr6: $52230081-52230165$ [-] & 1.223 & -0.962 & -2.185 & $1.11 \mathrm{E}-06$ & 134 \\
\hline $\operatorname{miR}-206-3 p$ & chr1: 20679010-20679082 [+] & 0.602 & -0.492 & -1.094 & $2.41 \mathrm{E}-06$ & 336 \\
\hline miR-31-3p & chr4: $88910557-88910662$ [-] & -0.823 & 0.897 & 1.72 & $1.11 \mathrm{E}-06$ & 100 \\
\hline miR-31-5p & chr4: $88910557-88910662$ [-] & -1.07 & 0.962 & 2.031 & $1.11 \mathrm{E}-06$ & 263 \\
\hline $\operatorname{miR}-335-5 p$ & chr6: 30741299-30741396 [+] & 1.152 & -0.175 & -1.327 & $1.80 \mathrm{E}-05$ & 237 \\
\hline $\operatorname{miR}-376 a-3 p$ & chr12: $109723781-109723848[+]$ & 1.016 & -0.382 & -1.398 & $2.90 \mathrm{E}-05$ & 24 \\
\hline $\operatorname{miR}-376 b-5 p$ & chr12: $109723458-109723539[+]$ & 0.945 & -0.146 & -1.091 & 2.04E-06 & 225 \\
\hline $\operatorname{miR}-377-3 p$ & chr12: $109740510-109740577[+]$ & 0.919 & -0.338 & -1.256 & 2.04E-06 & 517 \\
\hline $\operatorname{miR}-379-5 p$ & chr12: $109709060-109709125[+]$ & 1.172 & -0.292 & -1.464 & $1.11 \mathrm{E}-06$ & 73 \\
\hline miR-411-5p & chr12: $109710175-109710256[+]$ & 1.091 & -0.442 & -1.533 & $1.43 \mathrm{E}-06$ & 157 \\
\hline $\operatorname{miR}-434-3 p$ & chr12: $109594506-109594599[+]$ & 0.954 & -0.344 & -1.298 & 5.37E-06 & 155 \\
\hline $\operatorname{miR}-434-5 p$ & chr12: $109594506-109594599[+]$ & 1.08 & -0.394 & -1.475 & 2.04E-06 & 24 \\
\hline $\operatorname{miR}-511-3 p$ & chr2: $14261003-14261081[+]$ & 0.795 & -0.444 & -1.239 & 2.04E-06 & 467 \\
\hline miR-5617-5p & chrX: 20863126-20863182 [-] & -1.015 & 0.138 & 1.152 & $3.75 \mathrm{E}-06$ & 267 \\
\hline miR-691 & chr16: $74341990-74342067[-]$ & -0.897 & 0.242 & 1.139 & $2.06 \mathrm{E}-06$ & 413 \\
\hline miR-709 & chr8: $84086099-84086186[+]$ & -1.091 & 0.249 & 1.34 & 2.32E-06 & 445 \\
\hline
\end{tabular}

The Tables (1-4) are showing the only miRNAs where the absolute value of the log fold change is $>1$ (log fold change of 1 equals a fold change of $2\left(2^{\wedge} 1=2\right)$. For each comparison the fold change expression is listed as $\log 2$ transformed values in the $\log \mathrm{FC}$ column. Bold texts in microRNA tables are showing the up regulated miRNAs. Last column is showing the total number of target genes by the miRNA using miRDB database. Abbreviations: $\mathrm{FC}=$ fold change, mmu $=$ denotes name code for miRNA in mouse species.

mice compared to their WT littermates. These miRNAs may have implication in UVR-induced resistance via suppression of oncogenic signaling. Also, the possibilities of combinatorial regulation of miRNAs in their skin micro-environment cannot be ignored in absence of TNF $\alpha$. We have chosen $4 \mathrm{hr}$ post UVR time point for miRNA profiling as many epidermal physiological alterations takes place in epidermis at early UVR-exposure time points [22, 23]. Similarly, we can observe UVR-induced hyperplasia after $24 \mathrm{hr}$ time points in mice skin [24]. It has been shown that the microRNA mediated gene regulatory network is dysregulated during the process of carcinogenesis [25]. These miRNAs contribute as an additional layer of regulators or fine tuner during gene expression. This miRNA profiling study provides novel insight for future exploration of miRNAs in connection with UVR and their functional implication in skin carcinogenesis.

In the present study, one of the miRNA miR-31-5p ( $>2 \log$ FC) observed to be over expressed in microRNA profiling study and UVR-induced tumor sample in WT mice. Similarly, microRNA miR-31-3p is also over expressed $(\mathrm{FC}=1.72 \log \mathrm{FC})$ in mouse skin followed by acute UVR exposure $\left(2.0 \mathrm{~kJ} / \mathrm{m}^{2}\right)$ in initial miRNA profiling. It appears that both these mature miRNAs (miR-31-5p and $-3 p$ ) originated from two opposite arm of the same pre-miRNA. The over-expression of miR31-5p may have direct link with UVR. The increased expression of miR-31 is reported in cutaneous human SCC $[10,11]$. Conversely, the miRNA-31 is found to be down regulated in primary and metastatic melanoma 
Table 2: Differential expression pattern of miRNAs in WT and TNFa KO mice

\begin{tabular}{|c|c|c|c|c|c|}
\hline microRNAs & Location on chromosome & WT & TNFa KO & $\log$ FC & Gene targets \\
\hline $\operatorname{miR}-127-3 p$ & chr12: $109592846-109592915[+]$ & 1.089 & -0.622 & -1.711 & 12 \\
\hline $\operatorname{miR}-136-3 p$ & chr12: $109595327-109595388[+]$ & 1.027 & -0.488 & -1.515 & 32 \\
\hline $\operatorname{miR}-136-5 p$ & chr12: $109595327-109595388[+]$ & 1.246 & -0.631 & -1.877 & 275 \\
\hline $\operatorname{miR}-154-5 p$ & chr12: $109738433-109738498[+]$ & 0.811 & -0.442 & -1.253 & 201 \\
\hline $\operatorname{miR}-196 a-5 p$ & chr11: $96265164-96265265[+]$ & 1.441 & -1.284 & -2.724 & 137 \\
\hline $\operatorname{miR}-196 b-5 p$ & chr6: $52230081-52230165[-]$ & 1.223 & -0.757 & -1.979 & 134 \\
\hline $\operatorname{miR}-335-5 p$ & chr6: $30741299-30741396[+]$ & 1.152 & -0.132 & -1.284 & 237 \\
\hline $\operatorname{miR}-376 a-3 p$ & chr12: $109723781-109723848[+]$ & 1.016 & -0.807 & -1.823 & 24 \\
\hline $\operatorname{miR}-376 b-5 p$ & chr12: $109723458-109723539[+]$ & 0.945 & -0.222 & -1.167 & 225 \\
\hline $\operatorname{miR}-377-3 p$ & chr12: $109740510-109740577[+]$ & 0.919 & -0.449 & -1.368 & 517 \\
\hline $\operatorname{miR}-379-5 p$ & chr12: $109709060-109709125[+]$ & 1.172 & -0.616 & -1.788 & 73 \\
\hline $\operatorname{miR}-411-5 p$ & chr12: $109710175-109710256[+]$ & 1.091 & -0.609 & -1.7 & 157 \\
\hline $\operatorname{miR}-434-3 p$ & chr12: $109594506-109594599[+]$ & 0.954 & -0.439 & -1.393 & 155 \\
\hline $\operatorname{miR}-434-5 p$ & chr12: $109594506-109594599[+]$ & 1.08 & -0.51 & -1.59 & 24 \\
\hline miR-3065-3p & chr11: $120014767-120014853[+]$ & -0.699 & 0.745 & 1.444 & 253 \\
\hline $\operatorname{miR}-541-5 p$ & chr12: $109742409-109742498[+]$ & 0.732 & -0.574 & -1.306 & 164 \\
\hline $\operatorname{miR}-322-5 p$ & chrX: $53054255-53054349[-]$ & 0.66 & -0.368 & -1.028 & 613 \\
\hline
\end{tabular}

Table 3: Differential expression pattern of UVR-induced miRNAs in TNF $\alpha$ KO mice

\begin{tabular}{|l|l|l|l|l|l|}
\hline microRNAs & Location on chromosome & TNF $\alpha$ KO & TNF $\alpha$ KO + UVR & Log FC & $\begin{array}{l}\text { Gene } \\
\text { targets }\end{array}$ \\
\hline miR-196b-5p & chr6: 52230081-52230165 [-] & -1.284 & 0.714 & 1.998 & 134 \\
\hline miR-206-3p & chr1: 20679010-20679082 [+] & -0.757 & 0.522 & 1.278 & 336 \\
\hline
\end{tabular}

Table 4: Differential expression pattern of UVR-induced miRNAs in WT and TNF $\alpha$ KO mice

\begin{tabular}{|l|l|l|l|l|l|}
\hline microRNAs & Location on chromosome & TNF $\alpha$ KO+UVR & WT+UVR & log FC & $\begin{array}{l}\text { Gene } \\
\text { targets }\end{array}$ \\
\hline miR-196b-5p & chr6: $52230081-52230165[-]$ & 0.714 & -1.405 & 2.12 & 134 \\
\hline miR-206-3p & chr1: $20679010-20679082[+]$ & 0.522 & -0.962 & 1.484 & 336 \\
\hline miR-31-3p & chr4: $88910557-88910662[-]$ & -0.831 & 0.897 & -1.729 & 100 \\
\hline miR-31-5p & chr4: $88910557-88910662[-]$ & -0.992 & 0.962 & -1.954 & 263 \\
\hline
\end{tabular}


[26] and can pleiotropically act as an inhibitor of breast cancer metastasis [27]. Also, our bioinformatics analyses revealed that miR-31-5p target the PKCE gene, which is an endogenous photosensitizer which sensitizes the skin by enhancing UVR-induced cutaneous damage and development of cutaneous SCC [16].

A number of studies have explored the pattern of the global miRNA profiling in various cell lines and skin cancer $[11,12,28]$. In the present miRNA profiling study, most of the miRNAs are down regulated following TNF $\alpha$ deletion and UVR treatment. We also observed the suppression of miRNAs in SCC samples compared to uninvolved mice skin for miR-195-5p, miR-127-3p, miR-206-3p, miR-411-5p, miR-709-5p, and miR-322-5p. These observations are in corroboration with the earlier findings, where they have shown the suppression of various miRNAs in cancer $[29,30]$. The repression may be due to the direct impact of acute UVR or other indirect regulations involving biogenesis pathways, epigenetic modification, and alteration in transcriptional machinery $[30,31]$. We also observed the differential expression of miR-196a-5p, miR-127-3p, and miR-206-3p in our samples. These miRNAs are found to be differentially and highly expressed in skin hair follicles compared to epidermis [21]. These miRNAs may have some potential implication in the hair follicle morphogenesis and UVR signaling.

Notably, a single miRNA can target various gene targets and act on hundreds of mRNAs that contain complementary binding sites. These target genes may be the integral part of the same biological pathways. We looked at the synergistic role of up- and down-regulated miRNAs due to acute UVR to determine the pathways affected and implicated in the process of UVR-induced carcinogenesis. We found the pathways related to transcriptional misregulation in cancer, cell cycle, TGF- $\beta$ signaling, MAPK signaling, Wnt signaling, Ubiquitin mediated proteolysis, PI3K-Akt signaling targeted by more than one miRNA gene in both up- and downregulated miRNAs. Most of these signaling pathways are implicated in different types of skin cancer progression via direct as well as indirect involvement of UVR [32-36]. In our bio-informatics analysis, targeted genes and predicted pathways provide clues for further studies.

In conclusion, we determine UVR-induced expression profile of miRNAs in the skin of WT and $\mathrm{TNF} \alpha \mathrm{KO}$ mice. Bio-informatics based analysis revealed the miRNA targeted genes as well as the potential signaling pathways affected due to modulation of miRNAs following acute UVR exposure in epidermal skin. Our finding suggests that the single UVR exposure has pleotropic effects in the micro-environment of the skin, which can modulate various miRNAs and their target genes. Synergistically, the miRNAs can modulate the expression patterns of various genes in biologically relevant pathways linked to UVR-induced skin cancer.

\section{MATERIALS AND METHODS}

\section{Mice and treatments}

The mice used in the present study (WT and TNF $\alpha$ knock out) were on FVB background. The mice after genotyping were housed in groups of two to three in transparent plastic cages in light, humidity, and temperature-controlled rooms. The food and water were available ad libitum. The ages of the mice were 5-6 weeks at the time of experimentation. The dorsal hairs of the mice were shaved 3-4 days before experimentation. UVR source was Kodacel-filtered FS-40 sun lamps which comprises approximately $60 \% \mathrm{UVB}$ and $40 \%$ UVA. Mice were exposed to UVR $\left(2.0 \mathrm{~kJ} / \mathrm{m}^{2}\right)$ using a bank of six Kodacel-filtered sunlamps available in procedure rooms. UVR doses were routinely measured for its accuracy using a UVX radiometer. UVR lamps were purchased from National Biologicals Corporation, (Beachwood, $\mathrm{OH})$, Kodacel filters from Unique Photo Inc. (Fairfield, NJ), and UVX-radiometer from UVP (Upland, CA). The details about the generation of TNF $\alpha$ KO mice are described elsewhere [16]. Similarly, the UVR-induced skin carcinogenesis protocol is explained earlier in detail [24]. All mice were depilated one day prior to UVR exposure. Mice from both groups were sacrificed $4 \mathrm{hrs}$ post-UVR treatment. The animal protocols in the study were approved by the University of Wisconsin-Madison Research Animal Resources Committee in accordance with the National Institute of Health Guideline for the Care and Use of Laboratory Animals.

\section{RNA isolation, microRNA array profiling}

Total RNA was isolated from the dorsal epidermal skin of the mice using the Trizol (Invitrogen, USA) method. The concentration of RNA was determined by measuring the absorbance at $260 \mathrm{~nm}$ in a NanoDrop spectrophotometer. The quality of the total isolated RNA for microRNA profiling was evaluated by Exiqon Services, using an Agilent 2100 Bio analyzer (Agilent Technologies, Palo Alto, CA, USA). The integrity of the isolated RNA samples was confirmed on agarose gel. RNA samples from two mice $(\mathrm{n}=2$ each) in each group were pooled for profiling.

MiRNA array profiling experiment was conducted at Exiqon Services (Denmark). Briefly, a total of $750 \mathrm{ng}$ RNA from both sample and reference was labeled with $\mathrm{Hy} 3^{\mathrm{TM}}$ and $\mathrm{Hy} 5^{\mathrm{TM}}$ fluorescent label respectively, using the miRCURY LNA ${ }^{\mathrm{TM}}$ microRNA Hi-Power Labeling Kit, $\mathrm{Hy} 3^{\mathrm{TM}} / \mathrm{Hy} 5^{\mathrm{TM}}$. There were 1157 spots in triplicate on the miRNA array slide. The Hy $3^{\mathrm{TM}}$ and $\mathrm{Hy} 5^{\mathrm{TM}}$-labeled RNA samples were mixed pair-wise and hybridized to the miRCURY LNA ${ }^{\mathrm{TM}}$ microRNA Array 7th Gen, 
which contains capture probes targeting all registered mouse miRNAs in miRBASE 18.0. The hybridization was performed using a Tecan HS4800 ${ }^{\mathrm{TM}}$ hybridization station (Tecan, Austria) and slides were scanned and stored in an ozone free environment in order to prevent bleaching of fluorescent dyes. The labelled slides were scanned in Agilent G2565BA Microarray Scanner (Agilent Technologies, Inc., USA) and analyzed using the ImaGene ${ }^{\circledR}$ 9. The quantified signals were background corrected (Normexp with offset value 10), [37] and normalized using the regression algorithm global Lowess (LOcally WEighted Scatterplot Smoothing). Principle Component Analysis (PCA) was performed for quality control.

\section{Primers for miRNA}

To validate the miRNA profiling results, we have selected up- and down-regulated microRNAs and compared to their respective controls. The miRNAs chosen for validation having average $\mathrm{Hy} 3$ values (intensity of spot) $>7$, and $\log$ fold change values $>1$. All miRNA primers of mouse namely miR-31-5p, miR-196a-5p, miR127-3p, miR-206-3p, miR-411-5p, miR-709, miR-3225p, miR-32-5p, miR-33-5p, miR-376a-3p, miR-144-3p, and miR-136-5p were procured from Exiqon. U6 snRNA (mmu) was used as an internal control primer set. A detailed list of microRNA primers along with their target sequences is available online at Exiqon web site (http:// www.exiqon.com/plate-layout-files).

\section{cDNA synthesis, real-time reverse transcriptase polymerase chain reaction (RT-PCR)}

Reverse transcription reaction was set up using cDNA synthesis kit (Exiqon, miRCURY LNA ${ }^{\mathrm{TM}}$ Universal RT miRNA PCR, Polyadenylation and cDNA synthesis kit II product code 203301). Briefly, the template RNA $(5 \mathrm{ng} / \mu \mathrm{L}), 5 \mathrm{X}$ reaction buffer $(2 \mu \mathrm{L})$, enzyme mix $(1 \mu \mathrm{L})$, and nuclease free water was added together to make final volume to $10 \mu \mathrm{L}$. For cDNA synthesis reaction, PCR settings were as follow: $60 \mathrm{~min}$ at $42^{\circ} \mathrm{C}$, heat inactivation of reverse transcriptase for $5 \mathrm{~min}$ at $95^{\circ} \mathrm{C}$ and finally stored at $4^{0} \mathrm{C}$.

Before using cDNA for RT-PCR reaction, the required amount of cDNA was diluted $80 \mathrm{X}$ (1:80 dilution) in nuclease free water and used immediately. For running the RT-PCR reaction, a working solution was prepared with ExiLENT SYBR Green (Exiqon, product code 203402) master mix $(5 \mu \mathrm{L})$, PCR primer mix $(1 \mu \mathrm{L})$, diluted cDNA template $(4 \mu \mathrm{L})$ and the total volume was adjusted to $10 \mathrm{uL}$. The real time PCR reaction was set up in Bio-Rad machine. The RT-PCR program was set up as follows: $95^{\circ} \mathrm{C}$ for $10 \mathrm{~min}, 40$ amplification cycles at $95^{\circ} \mathrm{C}$,
$10 \mathrm{sec}$ at $60^{\circ} \mathrm{C}, 1 \mathrm{~min}$ ramp rate $1.6 \mathrm{C} / \mathrm{sec}$.

\section{Analysis of microRNA expression in real time}

To determine the fold change analysis in our mouse samples, we have calculated the differences in $\mathrm{Ct}$ values of our endogenous control (U6 snRNA) and miRNA samples. Briefly, first the $\mathrm{Ct}$ values for all the samples are extracted and delta $\mathrm{Ct}$ is calculated as the difference in $\mathrm{Ct}$ between microRNA target and endogenous control $\left[\Delta \mathrm{C}_{\mathrm{T}}=\mathrm{C}_{\mathrm{T}}\right.$ (target miRNA) - $\mathrm{C}_{\mathrm{T}}$ (endogenous control) $]$. Secondly, the $\Delta \Delta \mathrm{C}_{\mathrm{T}}$ is calculated $\left[\Delta \Delta \mathrm{C}_{\mathrm{T}}=\Delta \mathrm{C}_{\mathrm{T}}\right.$ (sample of interest) $-\Delta \mathrm{C}_{\mathrm{T}}$ (control sample)]. Normalization of target miRNA target gene expression in the sample of interest is determined as $2^{-\Delta \Delta C T}$. At final, the normalized expression level of control sample is set to 1 and change in target microRNA gene expression is determined as: Fold change in target microRNA expression $=1$ - normalized target miRNA expression in sample of interest.

\section{Bioinformatics tools for target prediction and pathway analysis}

For prediction of miRNA targets, we used freely available bioinformatics tools such as DNA intelligent analysis or DIANA (http://diana.cslab.ece.ntua.gr/), MIRANDA, Target Scan (http://www.targetscan. org/), and miRNA database or miRDB (http://www. mirbase.org/). These bioinformatics tools predict the miRNA and its putative targets on the basis of sequence complementarity in 5' and 3' UTRs along with various sequence based mathematical algorithms. We also used DIANA miRPath v.2.0 for investigating the combinatorial effects of UVR-induced microRNAs in various biologically relevant pathways [38]. For pathway analysis a threshold p-value 0.05 along with MicroT threshold 0.8 were used for both up- and down-regulated microRNAs. We have selected pathways union mode, which identifies all the significantly targeted pathways by the selected miRNAs. In brief, we used the DIANA-miRPath webserver to predict miRNA targets (in coding or 3'-UTR regions) using the DIANA-microT-CDS algorithm. We used the default settings ( $\mathrm{p}$ value 0.05 , and threshold score 0.8 ), which returned an average of 350 targets per miRNA. These observed predicted and/or validated interactions were subsequently combined with sophisticated merging and meta-analysis algorithms [38]. Information about the chromosomal localization of miRNA was obtained from miRDB. 


\section{Statistical analysis}

Limma [39] and differential expression analysis [40] packages were used to determine differentially expressed genes in the following comparisons: WT vs. WT+UVR, WT vs. TNF $\alpha \mathrm{KO}, \mathrm{TNF} \alpha \mathrm{KO}$ vs. TNF $\alpha \mathrm{KO}+\mathrm{UVR}$, and TNF $\alpha \mathrm{KO}+\mathrm{UVR}$ vs. WT+UVR. Adjusted p-value < 0.05 and $\mid \log _{2}$ fold-change (FC) $\mid>1$ were used as cutoff criteria. Differences in expression level of miRNAs in uninvolved skin (skin without tumor) and SCC were examined using unpaired t-test. $\mathrm{p} \leq 0.05$ was considered to be statistically significant.

\section{Abbreviations}

TNFa: tumor necrosis factor alpha; UVR: ultraviolet radiation; SCC: squamous cell carcinoma

\section{FUNDING}

This study was supported by the funding from the National Institutes of Health by CA102431 grant, and University of Wisconsin Carbone Cancer Center, Cancer Center Support Grant P30 CA014520.

\section{CONFLICTS OF INTEREST}

No potential conflicts of interest were disclosed.

\section{REFERENCES}

1. Molho-Pessach V and Lotem M. Ultraviolet radiation and cutaneous carcinogenesis. Curr Probl Dermatol. 2007; 35:14-27.

2. Ratushny V, Gober MD, Hick R, Ridky TW and Seykora JT. From keratinocyte to cancer: the pathogenesis and modeling of cutaneous squamous cell carcinoma. J Clin Invest. 2012; 122:464-472.

3. de Gruijl FR, van Kranen HJ and Mullenders LH. UVinduced DNA damage, repair, mutations and oncogenic pathways in skin cancer. J Photochem Photobiol B. 2001; 63:19-27.

4. Berton TR, Mitchell DL, Fischer SM and Locniskar MF. Epidermal proliferation but not quantity of DNA photodamage is correlated with UV-induced mouse skin carcinogenesis. J Invest Dermatol. 1997; 109:340-347.

5. Bartel DP. MicroRNAs: target recognition and regulatory functions. Cell. 2009; 136:215-233.

6. Ambros V. The functions of animal microRNAs. Nature. 2004; 431:350-355.

7. Bartel DP. MicroRNAs: genomics, biogenesis, mechanism, and function. Cell. 2004; 116:281-297.

8. Thomas M, Lieberman J and Lal A. Desperately seeking
microRNA targets. Nat Struct Mol Biol. 2010; 17:11691174.

9. Sand M, Gambichler T, Skrygan M, Sand D, Scola N, Altmeyer P and Bechara FG. Expression levels of the microRNA processing enzymes Drosha and dicer in epithelial skin cancer. Cancer Invest. 2010; 28:649-653.

10. Sand M, Skrygan M, Georgas D, Arenz C, Gambichler T, Sand D, Altmeyer P and Bechara FG. Expression levels of the microRNA maturing microprocessor complex component DGCR8 and the RNA-induced silencing complex (RISC) components argonaute-1, argonaute-2, PACT, TARBP1, and TARBP2 in epithelial skin cancer. Mol Carcinog. 2012; 51:916-922.

11. Bruegger C, Kempf W, Spoerri I, Arnold AW, Itin $\mathrm{PH}$ and Burger B. MicroRNA expression differs in cutaneous squamous cell carcinomas and healthy skin of immunocompetent individuals. Exp Dermatol. 2013; 22:426-428.

12. Xu N, Zhang L, Meisgen F, Harada M, Heilborn J, Homey B, Grander D, Stahle M, Sonkoly E and Pivarcsi A. MicroRNA-125b down-regulates matrix metallopeptidase 13 and inhibits cutaneous squamous cell carcinoma cell proliferation, migration, and invasion. J Biol Chem. 2012; 287:29899-29908.

13. Kraemer A, Chen IP, Henning S, Faust A, Volkmer B, Atkinson MJ, Moertl S and Greinert R. UVA and UVB irradiation differentially regulate microRNA expression in human primary keratinocytes. PLoS One. 2013; 8:e83392.

14. Balci S, Ayaz L, Gorur A, Yildirim Yaroglu H, Akbayir S, Dogruer Unal N, Bulut B, Tursen U and Tamer L. microRNA profiling for early detection of nonmelanoma skin cancer. LID - 10.1111/ced.12736 [doi]. Clin Exp Dermatol. 2015; 24:12736.

15. Syed DN, Lall RK, and Mukhtar H. MicroRNAs and photocarcinogenesis. Photochem Photobiol. 91(1):173-187. doi: 110.1111/php.12346. Epub 12014 Dec 12316.

16. Wheeler DL, Martin KE, Ness KJ, Li Y, Dreckschmidt NE, Wartman M, Ananthaswamy HN, Mitchell DL and Verma AK. Protein kinase C epsilon is an endogenous photosensitizer that enhances ultraviolet radiation-induced cutaneous damage and development of squamous cell carcinomas. Cancer Res. 2004; 64:7756-7765.

17. Wheeler DL, Ness KJ, Oberley TD and Verma AK. Protein kinase Cepsilon is linked to 12-O-tetradecanoylphorbol13-acetate-induced tumor necrosis factor-alpha ectodomain shedding and the development of metastatic squamous cell carcinoma in protein kinase Cepsilon transgenic mice. Cancer Res. 2003; 63:6547-6555.

18. Wheeler DL, Reddig PJ, Ness KJ, Leith CP, Oberley TD and Verma AK. Overexpression of protein kinase $\mathrm{C}$-\{epsilon $\}$ in the mouse epidermis leads to a spontaneous myeloproliferative-like disease. Am J Pathol. 2005; 166:117-126.

19. Moore RJ, Owens DM, Stamp G, Arnott C, Burke F, East 
N, Holdsworth H, Turner L, Rollins B, Pasparakis M, Kollias G and Balkwill F. Mice deficient in tumor necrosis factor-alpha are resistant to skin carcinogenesis. Nat Med. 1999; 5:828-831.

20. Suganuma M, Okabe S, Marino MW, Sakai A, Sueoka E and Fujiki H. Essential role of tumor necrosis factor alpha (TNF-alpha) in tumor promotion as revealed by TNF-alphadeficient mice. Cancer Res. 1999; 59:4516-4518.

21. Yi R, O'Carroll D, Pasolli HA, Zhang Z, Dietrich FS, Tarakhovsky A and Fuchs E. Morphogenesis in skin is governed by discrete sets of differentially expressed microRNAs. Nat Genet. 2006; 38:356-362.

22. Lowe M, Verma AK and Boutwell RK. Ultraviolet light induces epidermal ornithine decarboxylase activity. J Invest Dermatol. 1978; 71:417-418.

23. Epstein JH, Fukuyama K and Fye K. Effects of ultraviolet radiation on the mitotic cycle and DNA, RNA and protein synthesis in mammalian epidermis in vivo. Photochem Photobiol. 1970; 12:57-65.

24. Singh A, Singh A, Sand JM, Bauer SJ, Hafeez BB, Meske L and Verma AK. Topically Applied Hsp90 Inhibitor 17AAG Inhibits UVR-Induced Cutaneous Squamous Cell Carcinomas. J Invest Dermatol. 2015; 135:1098-1107.

25. Adams BD, Kasinski AL and Slack FJ. Aberrant regulation and function of microRNAs in cancer. Curr Biol. 2014; 24:R762-776.

26. Asangani IA, Harms PW, Dodson L, Pandhi M, Kunju LP, Maher CA, Fullen DR, Johnson TM, Giordano TJ, Palanisamy N and Chinnaiyan AM. Genetic and epigenetic loss of microRNA-31 leads to feed-forward expression of EZH2 in melanoma. Oncotarget. 2012; 3:1011-1025. doi: 10.18632/oncotarget.622.

27. Valastyan S, Reinhardt F, Benaich N, Calogrias D, Szasz AM, Wang ZC, Brock JE, Richardson AL and Weinberg RA. A pleiotropically acting microRNA, miR-31, inhibits breast cancer metastasis. Cell. 2009; 137:1032-1046.

28. Sand M, Sand D, Altmeyer P and Bechara FG. MicroRNA in non-melanoma skin cancer. Cancer Biomark. 2012; 11:253-257.

29. Lu J, Getz G, Miska EA, Alvarez-Saavedra E, Lamb J, Peck D, Sweet-Cordero A, Ebert BL, Mak RH, Ferrando AA, Downing JR, Jacks T, Horvitz HR and Golub TR. MicroRNA expression profiles classify human cancers. Nature. 2005; 435:834-838.
30. Chang TC, Yu D, Lee YS, Wentzel EA, Arking DE, West KM, Dang CV, Thomas-Tikhonenko A and Mendell JT. Widespread microRNA repression by Myc contributes to tumorigenesis. Nat Genet. 2008; 40:43-50.

31. Brueckner B, Stresemann C, Kuner R, Mund C, Musch T, Meister M, Sultmann H and Lyko F. The human let-7a-3 locus contains an epigenetically regulated microRNA gene with oncogenic function. Cancer Res. 2007; 67:1419-1423.

32. Pal HC, Athar M, Elmets CA and Afaq F. Fisetin inhibits UVB-induced cutaneous inflammation and activation of PI3K/AKT/ NFkappaB signaling pathways in SKH-1 hairless mice. Photochem Photobiol. 2015; 91:225-34.

33. Afaq F, Ahmad N and Mukhtar H. Suppression of UVBinduced phosphorylation of mitogen-activated protein kinases and nuclear factor kappa B by green tea polyphenol in SKH-1 hairless mice. Oncogene. 2003; 22:9254-9264.

34. Chan EF, Gat U, McNiff JM and Fuchs E. A common human skin tumour is caused by activating mutations in beta-catenin. Nat Genet. 1999; 21:410-413.

35. Bowden GT. Prevention of non-melanoma skin cancer by targeting ultraviolet-B-light signalling. Nature reviews Cancer. 2004; 4:23-35.

36. Javelaud D, Alexaki VI, Dennler S, Mohammad KS, Guise TA and Mauviel A. TGF-beta/SMAD/GLI2 signaling axis in cancer progression and metastasis. Cancer Res. 2011; 71:5606-5610.

37. Ritchie ME, Silver J, Oshlack A, Holmes M, Diyagama D, Holloway A and Smyth GK. A comparison of background correction methods for two-colour microarrays. Bioinformatics. 2007; 23:2700-2707.

38. Vlachos IS, Kostoulas N, Vergoulis T, Georgakilas G, Reczko M, Maragkakis M, Paraskevopoulou MD, Prionidis K, Dalamagas T and Hatzigeorgiou AG. DIANA miRPath v.2.0: investigating the combinatorial effect of microRNAs in pathways. Nucleic Acids Res. 2012; 40(Web Server issue):W498-504.

39. Ritchie ME, Phipson B, Wu D, Hu Y, Law CW, Shi W and Smyth GK. limma powers differential expression analyses for RNA-sequencing and microarray studies. Nucleic Acids Res. 2015; $43: \mathrm{e} 47$.

40. Smyth GK. Linear models and empirical bayes methods for assessing differential expression in microarray experiments. Statistical applications in genetics and molecular biology. 2004; 3:Article3. 